\title{
Study on the Impromptu Theme of English Speaking
}

\author{
Juan Yu \\ Wuhan Donghu University, Wuhan, Hubei, 43000
}

Keywords: Impromptu, English Speaking, Speaking Competition

\begin{abstract}
In the English improvisation contest, the contestants often do not know what to say and how to organize the speech effectively because of the lack of logical thinking. An analysis of the typical English impromptu lecture shows that social issues such as social issues, temporal issues, negative problems, geographical problems, and complex questions can be used to help the lecturers by using different logical organizational models quickly find the right impromptu speech content and how to organize it.
\end{abstract}

\section{Introduction}

Among the types of impromptu speeches, many are closely related to the social phenomena around the students. On the subject, the general can be from the personal - social three dimensions of the organization of speech content, and if the problem is directly related to the students, the general can also add the school this dimension, that is, personal - family - school - society four dimensions. For example, the following on the social aspects of the ant community, you can from the ant family, family, school and society to organize several aspects of speech content:

It is estimated that there are over 3million struggling college graduates, or "anttribes", living in big cities nationwide, China Business News reported. "Ant tribe" is a name given to low-paid college graduates who huddle together in cheap city dwellings. The pro-portion of people aged over 30is increasing among them. The report shows it is becoming harder for well-educated people who were born into poor families to gain fortune and success. What's your comment?

From the personal point of view of the ant family, the speaker can analyze their reasons for staying in a big city: someone is to study, some people are in order to realize their dreams, some people have work do not want to do, someone can not find work When the ant, someone is to escape. From the student's point of view, the speaker can analyze the college students can not find the right to work to bring many problems to the family. From the school point of view, the speaker can explore the reasons why graduates can not find the right job, is the school set up a professional or curriculum can not meet the needs of the community, or students own problems? Do schools have to make greater efforts to avoid graduates becoming ants From a social point of view, the speaker can analyze whether our society should provide more jobs and help for the ant. If this is a three-minute impromptu lecture topic, then from these four angles to the speech, enough players to play;

\section{Interactional Metadiscourse}

Halliday believed that the features of language are closely concerned with the command of using language. When we use the language, we have some command of the language. This kind of command is also called the functions of language. When we do some researches about the language, the elaboration of functions of language must be established in the description of language construction. To be frank, we cannot illustrate all the concrete functions of language. However, there are some common things in functions of language. That is called "metafunction". Metafuntion can be divided into three kinds. Those are ideational function, interpersonal function and textual function. Based on Halliday's three metafuntions of system functional grammar, ideational function and interpersonal one are two basic functions in language. The ideational function refers to that 
language serves as the reflection of the language. That means the self-conscious reflection from inner world based on the experience he or she has. Nobody can express his or her feeling or ideas through other medium. The only way we can use is language. The interpersonal function means that language has been used to establish and maintain the social relationship with other people. The textual function is the function to make combination with words and clauses into meaningful texts which can express complete meaning. This kind of function combines language itself with the context features of the language. According to the functional approach which is regarded metadiscourse as a way of elaborating the interpersonal relations, Hyland proposed the categories of interpersonal model of metadiscourse. Transitions include some conjunctions and adverbial phrases. Generally speaking, they only play pragmatic function and do not have many concrete meanings. They also do some connections between the components. No matter what function they serve, they have to link the components to elaborate the complete ideas. It may help the readers to understand the discourse. They are equipped with three discourse roles: comparison, consequence and addition. Comparisons refer to the make comparisons of arguments between their similarities and differences such as similarly, however, but, in contrast. Consequence means that to give a certain conclusion such as therefore, as a result, in conclusion, consequently and so on. Addition shows that to add some other components to an argument like and, moreover, furthermore etc.

The interactional one shows the interactional relationship between the writer and reader. The writer takes some actions to remind the reader of understanding the argument information. Essentially speaking, the metadiscourse here is evaluative and participative and also reflects the degree of the kinship between the reader and the writer, the writer's attitude and the degree of readers' engagement. There are five subcategories too.

Engagement markers are devices that clearly establish the relationship with the readers. They don't only attract reader's attention. More importantly, engagement markers regard the readers as discourse participants to interact with the writer. There are two main purposes that engagement marker would be achieved: firstly, they fulfill the readers' expectation of inclusion and solidarity and regard them as participants in an argument with pronouns (we, you, your etc.) and interjections (by the way, you may notice etc.); secondly, make the readers into discourse properly, predict the objections and guide the readers to specific elaboration such as see, note, consider, you can see that etc.

Hedges are the markers that make the information seem like the writer's opinion rather than a fact. Might, perhaps, possible etc. are often used in this way. The function of hedges is to weaken the assertion of the proposition. The text with hedges also indicate that the writer's plausible reasoning rather than assertion of the knowledge and confidence. The writer basically uses indirect way to express the propositional information.

Attitude markers express the writer's emotional feeling rather than his or her rational attitude. The markers indicate information of surprise, commitment, frustration and so forth. Attitude verbs, adjectives and adverbs are often used in the text definitely. For example, agree, prefer, surprisingly, unfortunately etc.

\section{Interactive Metadiscourse}

The interactive metadiscourse means that the writer should concern with the audiences' knowledge backgrounds, interests, expectations and abilities to comprehend and absorb the writer's intended meaning. Also, it truly gives the writer some helps to raise his or her arguments and then ideal illustration will be realized by the listeners. Therefore, there is no doubt that there are 514 interactive metadiscourse items in 20 complete speeches which about 9472 words in total. The proportion of each kind of metadiscourse resources are shown in the chart below.

It clearly shows that imbalanced proportion is distributed in interactive metadiscourse resources. Under the interactive metadiscourse, transitions are frequently used with $45 \%$ in total. Then it is followed by the frame markers with $34 \%$ in total. Actually, it is the second high frequency use of interactive metadiscourse resources. The following rankings are code glossses with 15\%, evidentials with $5 \%$, endophoric markers with only $1 \%$. The data reveals that transitions and frame 
markers are in dominant places. On one hand, transitions assistant the writer to organize the texts more coherent. On the other hand, frame markers in text are used to link different parts in order.

Transitions include some conjunctions and adverbial phrases. Generally speaking, they only play pragmatic function and do not have many concrete meanings. They also do some connections between the components. No matter what function they serve, they have to link the components to elaborate the complete ideas. It may help the readers to better understanding the discourse. They are equipped with three discourse roles: comparison, consequence and addition. Comparisons refer to the make comparisons of arguments between their similarities and differences such as similarly, however, but, in contrast. Consequence means that to give a certain conclusion such as therefore, as a result, in conclusion, consequently and so on. Addition shows that to add some other components to an argument like and, moreover, furthermore etc. The corpus reflects a large number of the use of conjunctions such as and, but, so, because.

It easily finds that there is a high frequency of frame markers in the data. Frame markers reflect the boundaries of sentences and paragraphs or components in discourse. This kind of markers often offers some framing information about component of the discourse. They always plays four main roles: firstly, place some components of the text or arguments orderly (first, next, then etc.); secondly, to mark text stages in discourse itself (to sum up, finally, to conclude, in conclusion etc.); thirdly, to elaborate the discourse goals (my purpose is, those are the reasons why, I argue here etc.); Fourth, markers give some hints to the audience that the speaker's topic is going to change very soon (well, ok, right etc.) They assistant the audience to comprehend the discourse better.

Code glosses are basically function as adding certain information by paraphrase or explaining in other ways such as such as, e.g., namely, for example etc. The function of this kind of devices is to make sure the reader can comprehend the writer's intention. Code glosses indicate that the writer predicts the reader's background knowledge and use more common words to give explanation. From the chart, we can easily find that code glosses account for only $4.55 \%$ of all metadiscourse. The speaker usually use that is, such as, for example, I mean and or to estimate the listeners' knowledge background.

The code glosses such as that is, such as, for example, I mean and or above function as adding certain information by paraphrase or explain in some common words to make sure the reader understand the writer's intended meaning. However, there are still some differences among them I mean and that is are generally used to give explanation to the former word or sentences; such as and for example are used to illustrate the speaker's idea through examples. It shows that there is maybe another circumstance or choice. Although the code glosses just occupy a small part of all metadiscourse, we cannot deny their function to the discourse itself. In addition, most of the listeners are English teachers, students in English major or English learners. Therefore, it may quite unnecessary for them if they uses too much code glosses.

Frame markers reflect the boundaries of sentences and paragraphs or components in discourse. This kind of markers often offers some framing information about component of the discourse. They always play four main roles: firstly, to place some components of the text or arguments orderly (first, next, then etc.); secondly, to mark text stages in discourse itself (to sum up, finally, to conclude, in conclusion etc.); thirdly, to elaborate the discourse goals (my purpose is, those are the reasons why, I argue here etc.); Fourth, markers give some hints to the audience that the speaker's topic is going to change very soon (well, ok, right etc.) They assistant the audience to comprehend the discourse better.

\section{Conclusion}

Speaking is a speaker in a specific situation, with the language of the language and language, the face of the audience to express their views, to express feelings, so as to reach the audience of a realistic social practice, this definition is great The degree is only an ideal professional realm. For non-English majors' English impromptu speeches, it is not easy to do the perfect thing. It requires the speaker to have four or more English proficiency, rich vocabulary, good English pronunciation, oral expression, good psychological quality And the power of inspiration, but also requires students 
to have a wide range of knowledge and social aspects of life and other social hot spots of the views. Interested students in this area from the above to strengthen the efforts to lay a solid foundation of the language, and continue to enrich the knowledge, diligent practice, pay attention to reasonable training methods, standing in the English improvisation speech contest platform should also be calm.

\section{References}

[1] Gong Jun. Meta-discourse research: reflection and criticism [J]. Foreign Language Journal. 2010 (05)

[2] Tang Jianping. Meta-discourse research review [J]. Shandong Foreign Language Teaching. 2010 (01)

[3] Yang Xinzhang. Meta-discourse and linguistic functions [J]. Foreign Language and Foreign Language Teaching. 2007 (12)

[4] Xu Jiujiu. On the scope and classification of meta-discourse [J]. Contemporary Linguistics. 2006 (04)

[5] Xu Haiming, Pan Haiyan. Summary of Theoretical and Empirical Studies of Meta-discourse [J]. Foreign Languages (Journal of Shanghai International Studies University) 2005 (06)

[6] Liu Yi. On functional functional linguistics meta-functional theory and its application [J]. Journal of Northeastern University (Social Science Edition). 2004 (03)

[7] Hu Qing. College students English improvisation speech skills [J]. Journal of Hunan Light Industry College. 2000 (01) 